\title{
Menopause Status
}

National Cancer Institute

\section{Source}

National Cancer Institute. Menopause Status. NCI Thesaurus. Code C106541.

An indicator as to whether the female subject is in menopause. 